\title{
Prevalence of the Respiratory Allergies among Adult Population in the City of Skopje in Relation to Climatic Change and Change in Pollen Micro Flora
}

\author{
Jovanka Karadzinska-Bislimovska ${ }^{1}$, Jordan Minov ${ }^{1}$, Vladimir Kendrovskii ${ }^{2}$, Snezana Milkovska ${ }^{1}$, \\ Saso Stoleski ${ }^{1}$, Dragan Mijakoski ${ }^{1}$ \\ ${ }^{1}$ Insitute for Occupational Health of R. Macedonia, Skopje-WHO Collaborating Center and GA ${ }^{2}$ LEN Collaborating Center, Skopje, \\ Republic of Macedonia; ${ }^{2}$ Institute for Public Health of R. Macedonia, Skopje, Republic of Macedonia. \\ Email: bislimovska_j@yahoo.com
}

Received July $12^{\text {th }}, 2012$; revised August $17^{\text {th }}, 2012$; accepted September $18^{\text {th }}, 2012$

\begin{abstract}
Introduction: Climate change may have an impact of prevalence and severity of respiratory allergies causing changes in the concentrations, distribution, dispersion patterns, and allergenic potential of aeroallergens in the environment. Objective: To assess the prevalence of atopy, sensitization to common pollen allergens, and respiratory allergies (allergic rhinitis and asthma) among adult population in the city of Skopje in relation to changes in pollen distributions caused by climate change and particularly maximum temperature, in the period 1996-2010. Methods: Aeropalinological measurements in the city of Skopje were performed by volumetric method in the period 1996-2009. Serial cross-sectional studies on the prevalence of atopy, sensitization to common pollen allergens, allergic rhinitis and asthma in adults by standardized methodology were conducted in defined critical periods (1996, 2003, 2007/2008 and 2009/2010). Evaluation of examined subjects included completion of a questionnaire, skin prick tests (SPT) to common inhalant allergens, and lung function tests. Results: Data from aeropalinological measurements showed differences in the pollen concentrations, as well as in the duration of pollen season for some pollen types. The prevalence of atopics was similar in all critical periods, and the prevalence of sensitization to common pollen allergens was slightly higher in the last study than in the study performed in 1996. We registered increase in the prevalence of allergic rhinitis in the examined period (11.5\% in 1996 to $17.4 \%$ in 2009/2010) followed by increase in the prevalence of rhinitics sensitized to common pollen allergens. The prevalence of allergic asthma was significantly higher in the study conducted in 2009/2010 than in the study conducted in $1996(5.1 \%$ vs. $2.1 \%, P=0.037)$ followed by slightly higher prevalence of asthmatics sensitized to common pollen allergens in the same period. Conclusions: Registered changes in the prevalence of sensitization to common pollen allergens, as well as in the prevalence of subjects with respiratory allergies sensitized to these allergens, even statistically non-significant, indicate the need of further monitoring and investigation in order to assess the association between climate change with change in pollen micro flora and related allergic disorders.
\end{abstract}

Keywords: Aeropalinological Measurements; Allergic Rhinitis; Allergic Sensitization; Asthma; Atopy

\section{Introduction}

Respiratory allergic disease became a global public health problem due to the substantial increase in their prevalence registered in the last three decades. Published data indicate prevalence of allergic rhinitis (AR) from $3.8 \%$ to $20.6 \%$ of the general population $(13 \%-15 \%$ in Finland, 4\% - 8.6\% in Switzerland, 9.6\% in the UK, $8.7 \%$ in Germany) $[1,2]$. According to the the studies carried out by the Institute for Occupational Health of Republic of Macedonia (IOH of RM), Skopje-WHO Collaborating Center and $\mathrm{GA}^{2} \mathrm{LEN}$ Collaborating Center, the prevalence of AR in adults in R. Macedonia in 1995 was $11.5 \%$, while in 2003 it was $20.8 \%$ [3]. The increas- ing prevalence in the last decades has been noted even for asthma. In the whole Western Europe asthma has doubled in 10 years according to the Institute of Allergy UCB of Belgium [4-6]. The studies carried out by the IOH of RM, Skopje indicated higher asthma prevalence in adults in R. Macedonia in 2003 than in 1995 (5.4\% vs. 3.2\%) [7,8].

Despite significant increase in the prevalence of respiratory allergies has been observed, the reasons for such an increase still remain unclear. Both environmental and host susceptibility factors seem to contribute. As the increase is registered in a short period of time (i.e. in a few decades), it is more likely that environmental factors, such as aeroallergens, air pollution, infections, diet, lifestyle, etc., play a greater role [9]. Exposure to environmental 
aeroallergens, such as pollens (tree, grass, and weed), molds, house dust mites, Blatella germanica, and pets, are considered as one of the main environmental risk factor for respiratory allergies [10].

Climate change, causing increase in temperature and humidity, as well as changes in the amount, distribution, and intensity of precipitation events, can impact the production, distribution, dispersion, and allergenic potential of aeroallergens in the environment that may result in changes in the prevalence and severity of respiratory allergic diseases [11, 12]. Air pollutants, also affected by climatic changes, can independently, and in conjunction with aeroallergens, cause and exacerbate respiratory allergic diseases [13].

Climate change has already been regisatered over the past 50 years, with global average temperature increase by more than $0.5^{\circ} \mathrm{C}$, with increase in the frequency of hot days and decrease in the frequency of cold nights [14]. The largest increase of air temperature in R. Macedonia is expected in the summer season, associated with a strong decrease in precipitation. According to the comparison of the results from the empirical downscaling and the Global Circulatory Model output, local projections show a more intensive increase in the air temperature in winter and in spring [15].

As a part of the WHO project "Protecting health from climatic change", Top task "National climate change adaptation strategy for health systems is developed", Task "Climate change vulnerability assessment is revised and recommendations for its improvement are provided", supported by WHO Country Office Skopje, Institute of Occupational Health of RM as a WHO Collaborating Center in cooperation with Institute of Public Health, performed a study on the impact of climate change as well as the impact of current and future burden of the ambient temperature on pollen micro-flora related to the respiratory allergies among adult population in the city of Skopje. Data from the evaluation of the characteristics of pollen micro flora (species, count, distribution, season variations, etc.) in defined critical periods (1996, 2003, $2007 / 2008$, and 2009/2010) concerning specific meteorological parameters (weather and humidity) are in detail presented in the article "The impact of maximum temperature and climate change to current and future pollen distribution in Skopje, R. Macedonia" [16]. In the present study we report our findings on prevalence of atopy, sensitization to common pollen allergens, and respiratory allergies (AR and asthma) among adult population in the city of Skopje in the critical periods mentioned above in relation to registered changes of pollen micro flora.

\section{Methods}

\subsection{Study Design and Setting}

The study was designed as a retrospective research. Data on average maximum weekly temperature for Skopje, obtained by the National Hydrometeorological Office, for the period 1994-2009 were related to specific pollen weekly distribution data for 1996, 2003, 2007 and 2009. In addition, serial cross-sectional studies on the prevalence of atopy, sensitization to common pollen allergens, $\mathrm{AR}$, and asthma were conducted in the Institute for Occupational Health of R. Macedonia-WHO Colaborating Center and $\mathrm{GA}^{2} \mathrm{LEN}$ Collaborating Center in the defined critical periods (1996, 2003, 2007/2008 and 2009/2010).

\subsection{Aeropalinological Measurements}

Pollen monitoring was conducted in Skopje $\left(42^{\circ} 01^{\prime} \mathrm{N}\right.$, $21^{\circ} 27^{\prime} \mathrm{E}$ at the altitude of $275 \mathrm{~m}$ above sea level), situated in the Skopje Valley. Pollen samples were collected by the Hirst volumetric method with a LANZONI VPPS 2000 sampler in 1996, 2003, 2007 and 2009. The trap was situated on the roof that was approximately 9 meters above the ground level. The concentration of 9 types of pollen grains (Betula, Cupressaceae, Quercus, Fraxinus, Platanus, Poaceae, Urticcaceae, Plantago and Chenopodiaceae) was presented as an annual pollen sum and as a weekly pollen sum $\left(\mathrm{pg} / \mathrm{mm}^{3}\right)$.

\subsection{Study Subjects}

A sample of 120 to 200 randomly selected adults (184 in 1996, 200 in 2003, 160 in 2007/2008, and 126 in 2009/ 2010) similar by their demographic characteristics was examined in each period. Evaluation of examined subjects included completion of a questionnaire, skin prick tests (SPT) to common inhalant allergens, and lung function tests.

\subsection{Questionnaire}

All subjects were interviewed by a physician who filled the questionnaire. The questionnaire included questions on respiratory and nasal symptoms in the last 12 months. Respiratory symptoms in the last 12 months (cough, phlegm, dyspnoea, wheezing, and chest tightness) were documented using the European Community for Coal and Steel questionnaire (ECCS-87), and the ECRHS questionnaire [17,18]. Nasal symptoms in the last 12 months (sneezing, itching, runny nose, and blocked nose) were also evaluated. The questionnaires also included questions about smoking habit, lifestyle, housing, environmental and workplace exposures, medication use, and family history of allergic and respiratory disorders.

\subsection{Skin Prick Tests (SPT)}

SPT to common inhalant allergens were performed on the volar part of the forearm using allergen extracts (Torlak, Serbia) of mixed tree pollens (Betula, Cupressa- 
ceae, Quercus, Fraxinus, Platanus, Populus, and Acer), mixed grass pollens (Poaceae), mugwort (Artemisia vulgaris), goosefoot (Chenopodiaceae spp.), plantain (Plantago lanceolata), Ambrosia elatior, molds (Alternaria alternate and Penicillium notatum), Dermato-phagoides pteronyssinus, Blatella germanica, cat fur, dog hair, and feathers mixed (chicken and duck feathers). All tests included positive $(1 \mathrm{mg} / \mathrm{mL}$ histamine $)$ and negative $(0.9 \%$ saline) controls. Following the recommendations of the European Academy of Allergology and Clinical Immunology (EAACI), the SPT were considered positive if the mean wheal diameter 20 min after allergen application was larger than $3 \mathrm{~mm}[19]$.

\subsection{Lung Function Tests}

Spirometry, including measures of forced vital capacity (FVC), forced expiratory volume in one second $\left(\mathrm{FEV}_{1}\right)$, $\mathrm{FEV}_{1} / \mathrm{FVC} \%$, maximal expiratory flow at $50 \%, 75 \%$ and $25 \%-75 \%$ of $\mathrm{FVC}\left(\mathrm{MEF}_{50}, \mathrm{MEF}_{75}\right.$ and $\mathrm{MEF}_{25-75}$, respectively), was performed recording the best of three measurements. The results were expressed as percentages of the predicted values, according to the European Community for Coal and Steel (ECCS) norms [20].

Histamine challenge was performed according to the European Respiratory Society (ERS)/American Thoracic Society (ATS) recommendations $[21,22]$. The test was considered positive if provocative concentration $20-\mathrm{PC}_{20}$ (i.e. the concentration of histamine causing a $20 \%$ fall in $\mathrm{FEV}_{1}$ ) was equal or less than $4 \mathrm{mg} / \mathrm{mL}$. In the subjects with reduced lung function, bronchodilator test with inhaled salbutamol was performed. According to the actual ATS/ERS recommendations, the test was considered positive if the increase of the $\mathrm{FEV}_{1}$ value after bronchodilator application was equal or more than $12 \%$ compared to the baseline value [23].

\subsection{Diagnostic Criteria for Certain Allergic Entities}

Atopy was defined as a presence of at least one positive SPT to standard inhalant allergens [24].

Sensitization to common pollen allergens was defined as at least one positive SPT to common pollen allergens.

Allergic rhinitis was defined by positive history of one or more rhinitis symptoms associated with positive SPT to pollen allergens.

Asthma was defined by history of one or more asthmatic symptoms or use of asthma medications associated with positive histamine challenge or positive bronchodilator test in the subjects with reduced lung function.

\subsection{Statistical Analysis}

The weekly numbers of pollen distributions were related to the average weekly maximum temperature on the same week using regression statistical analyses.

Continuous variables from the serial studies were expressed as mean values with standard deviation (SD) and nominal variables as numbers and percentages. The chisquare test (or Fisher's exact test where appropriate) was used for testing difference in prevalence. A $P$-value below 0.05 was considered statistically significant. Statistical analysis was performed using the Statistical Package for the Social Sciences (SPSS) version 17.0 for Windows.

\section{Results}

The current burden of the weather maximum temperature in the city of Skopje in the period 1994-2009 were in the range from -0.7 to $2.1^{\circ} \mathrm{C}$, i.e. February $\left(-0.3^{\circ} \mathrm{C}\right)$, March $\left(2.1^{\circ} \mathrm{C}\right)$, April $\left(0.5^{\circ} \mathrm{C}\right)$, May $\left(0.4^{\circ} \mathrm{C}\right)$, June $\left(-0.5^{\circ} \mathrm{C}\right)$, July $\left(0.3^{\circ} \mathrm{C}\right)$, August $\left(0.7^{\circ} \mathrm{C}\right)$, September $\left(-0.7^{\circ} \mathrm{C}\right)$ and October $\left(1.1^{\circ} \mathrm{C}\right)[16]$.

The regression beta coefficient for the total weekly pollens (Betula, Cupressaceae, Quercus, Fraxinus, Platanus, Poaceae, Urticcaceae, Plantago and Chenopodiaceae) as a function of the weekly maximum temperature in Skopje during the examined years was not statistically significant. The regression beta coefficient $(b=-0.23)$ for the total number of weekly pollens of Cupressaceae as a function of the weekly maximum temperature in Skopje during whole examined years was statistically significant $(P=0.020)$.

There was a progressive increase of duration of the pollen season for Platanus, Urticcaceae, Quercus, Plantago, and Chenopodiaceae in the period 1996-2010. Distribution of pollens increased in three main periods: early spring (March) with the main presence of the Cupressaceae, Fraxinus, and Poaceae type; spring (April-June), characterized by Betula, Quercus and Platanus type; and summer (July-August), characterized by Urticcaceae, Plantago and Chenopodiaceae type.

Demographic characteristics of the subjects enrolled in the serial studies are given in Table 1.

Prevalence of subjects with atopy in the studies performed in the critical periods was similar (Figure 1).

Prevalence of sensitized to common pollen allergens in the study performed in 2009/2010 was non-significantly higher then their prevalence obtained in the study performed in $1996(19.8 \%$ vs. $16.9 \%, P=0.124$; Chi-square test) (Figure 2).

We found similar prevalence of atopics sensitized to grass and weed pollens in all critical periods. The prevalence of atopics sensitized to tree pollens was lower than the prevalence of atopics sensitized to grass and weed pollens. This difference in the studies performed in 2003 and in 2007/2008 achieved statistical significance, i.e. in 
in Relation to Climatic Change and Change in Pollen Micro Flora

Table 1. Demographics of the subjects included in the serial studies.

\begin{tabular}{|c|c|c|c|c|}
\hline & Study performed in 1996 & Study performed in 2003 & Study performed in $2007 / 2008$ & Study performed in $2009 / 2010$ \\
\hline Study subjects & 184 & 200 & 160 & 126 \\
\hline $\mathrm{M} / \mathrm{F}$ ratio & 0.9 & 0.8 & 0.8 & 0.9 \\
\hline Mean age (years) & $39.7 \pm 14.3$ & $38.1 \pm 12.7$ & $40.2 \pm 15.8$ & $37.8 \pm 13.2$ \\
\hline Mean body mass index & $25.6 \pm 3.9$ & $25.2 \pm 4.7$ & $26.0 \pm 4.9$ & $25.4 \pm 3.1$ \\
\hline Daily smokers & $41.5 \%$ & $45.7 \%$ & $37.9 \%$ & $36.6 \%$ \\
\hline Ex-smokers & $6.5 \%$ & $9.0 \%$ & $6.3 \%$ & $7.9 \%$ \\
\hline Passive smokers & $19.1 \%$ & $24.2 \%$ & $25.0 \%$ & $23.5 \%$ \\
\hline
\end{tabular}

Numbers (\%) are given, unless otherwise stated. M: male; F: female.

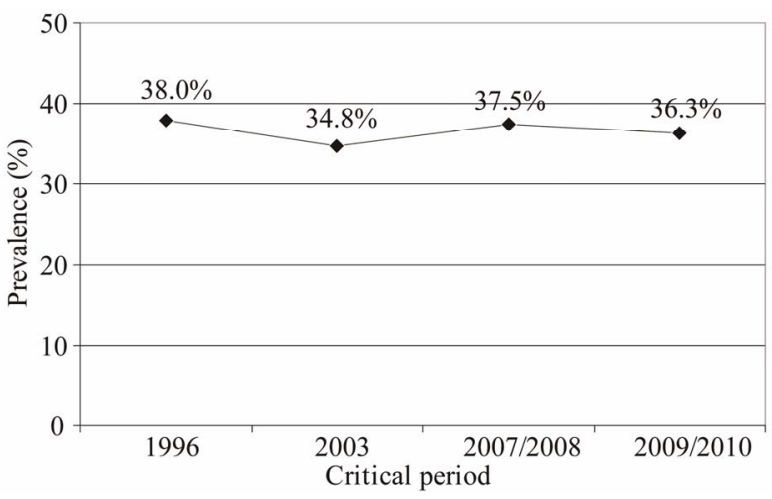

Figure 1. Prevalence of subjects with atopy in the studies performed in the critical periods: $38.0 \%$ (1996); $34.8 \%$ (2003); $37.5 \%$ (2007/2008); and 36.3\% (2009/2010).

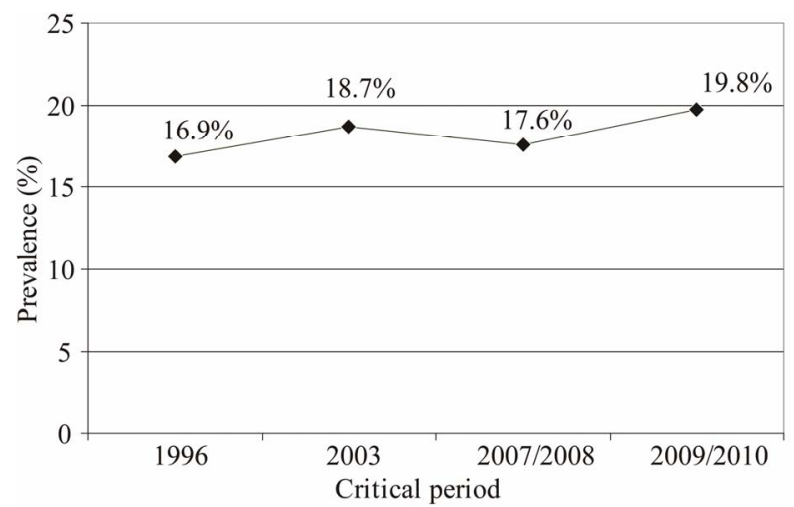

Figure 2. Prevalence of subjects sensitized to common pollen allergens in the studies performed in the critical periods: $16.9 \%$ in $1996,18.7 \%$ in $2003,17.6 \%$ in $2007 / 2008$ to $19.8 \%$ in $2009 / 2010$.

the study performed in 2003 the prevalence of subjects sensitized to tree pollens was significantly lower than the prevalence of subjects sensitized to grass and weed pollens (5.5\% vs. $12.8 \%, P=0.047$; Chi-square test and $5.5 \%$ vs. $14.3 \%, P=0.038$; Chi-square test, respectively), as well as in the study performed in $2007 / 2008$ (4.3\% vs. $13.1 \%, P=0.031$; Chi-square test and $4.3 \%$ vs. $10.6 \%, P=$ 0.043; Chi-square test, respectively) (Figure 3).

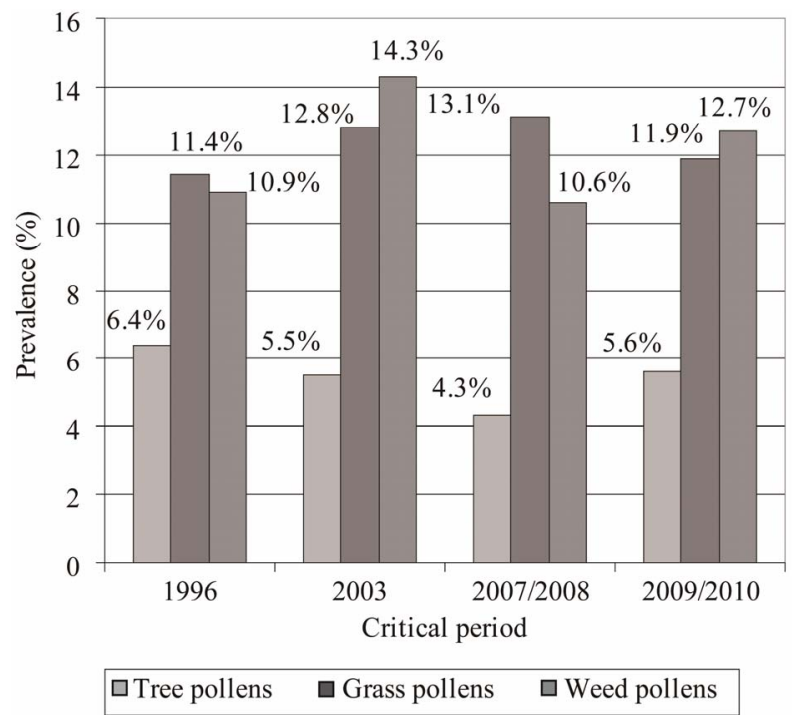

Figure 3. Prevalence of atopics sensitized to tree, grass, and weed pollens in the studies performed in the critical periods: $6.4 \%, 11.4 \%$, and $10.9 \%$, respectively $(1996) ; 5.5 \%, 12.8 \%$, and $14.3 \%$, respectively (2003); $4.3 \%, 13.1 \%$, and $10.6 \%$, respectively $(2007 / 2008)$; and $5.6 \%, 11.9 \%$, and $12.7 \%$, respectively (2009/2010).

Prevalence of subjects with AR varied from $11.5 \%$ in the study performed in $1996,8.5 \%$ in the study performed in 2003, 13.2\% in the study performed in $2007 /$ 2008 to $17.4 \%$ in the study performed in $2009 / 2010$ (Figure 4). There was no significant difference in the AR prevalence in the studies performed in the critical periods.

Prevalence of subjects with AR sensitized to common pollen allergens was slightly higher in the studies performed in 2007/2008 and in 2009/2010 than their prevalence registered in the study performed in 1996 (9.3\% vs. $7.6 \%, P=0.178$; Chi-square test and $8.7 \%$ vs. $7.6 \%, P=$ 0.213; Chi-square test, respectively) (Figure 5).

Prevalence of subjects with asthma was significantly higher in the studies performed in 2009/2010 and in $2007 / 2008$ than in the study performed in $1996(10.3 \%$ vs. $3.2 \%, P=0.026$; Fisher's exact test and $7.2 \%$ vs. 


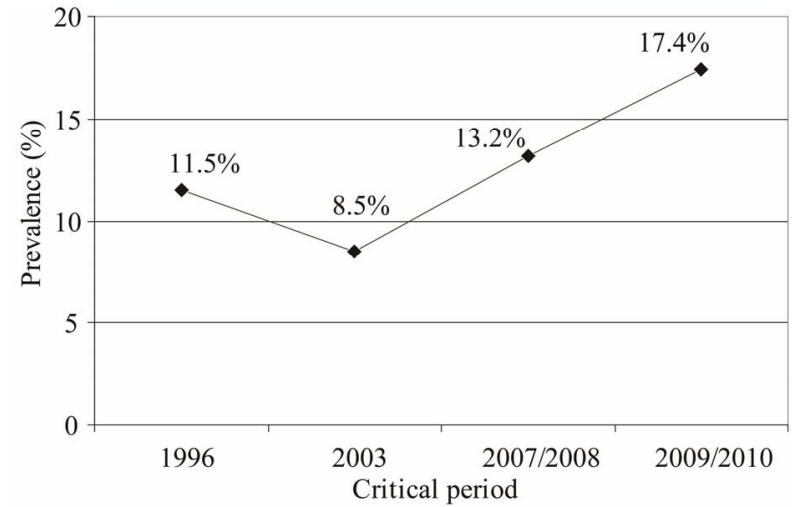

Figure 4. Prevalence of subjects with AR in the studies performed in the critical periods: $11.5 \%$ in 1996 ; $8.5 \%$ in 2003 ; $13.2 \%$ in $2007 / 2008$; and $17.4 \%$ in $2009 / 2010$.

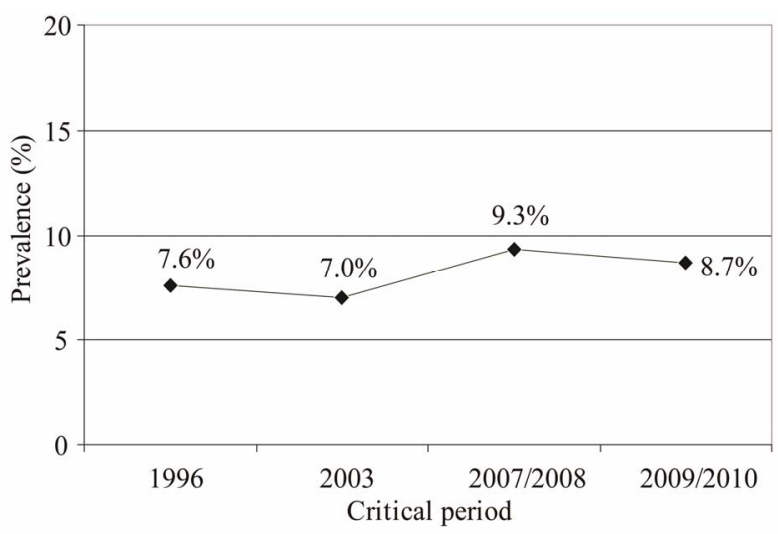

Figure 5. Prevalence of subjects with AR sensitized to common pollen allergens in the studies performed in the critical periods (1996, 2003, 2007/2008, and 2009/2010): $7.6 \%$ (1996), 7.0\% (2003), 9.3\% (2007/2008), and 8.7\% (2009/ 2010).

$3.2 \%, P=0.043$; Fisher's exact test, respectively) (Figure 6).

Prevalence of allergic asthma in examined subjects was significantly higher in the study performed in 2009/ 2010 than in the study performed in 1996 (5.1\% vs. $2.1 \%$, $P=0.037$; Fisher's exact test) (Figure 7).

The most important common inhalant allergen in the subjects with allergic asthma was mite sensitization. The prevalence of subjects with allergic asthma sensitized to Dermatophagoides pteronyssinus varied from $1.8 \%$ in the study carried out in 1996 to $4.0 \%$ in the study performed in 2009/2010. Prevalence of subjects with allergic asthma sensitized to common pollen allergens in the studies performed in 2007/2008 and in 1009/2010 was slightly higher than their prevalence in the study performed in $1996(2.1 \%$ vs. $1.1 \%, P=0.087$; Fisher's exact test and $1.7 \%$ vs. $1.1 \%, P=0.118$; Fisher's exact test, respectively) (Figure 8).

The course of prevalence of the respiratory allergies-

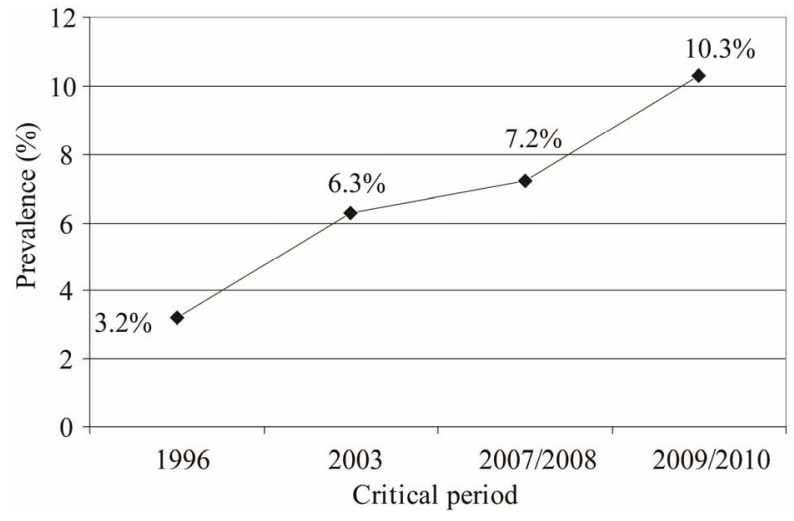

Figure 6. Prevalence of subjects with asthma in the studies performed in the critical periods: $3.2 \%$ (1996), $6.3 \%$ (2003), $7.2 \%(2007 / 2008)$, and $10.3 \%(2009 / 2010)$.

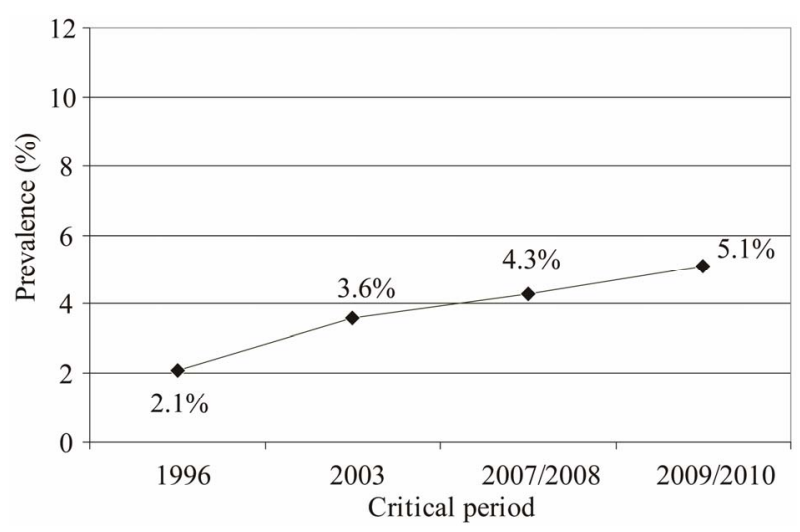

Figure 7. Prevalence of asthma in examined subjects in the studies performed in the critical periods: $2.1 \%$ (1996), $3.6 \%$ (2003), 4.3\% (2007/2008), and 5.1\% (2009/2010).

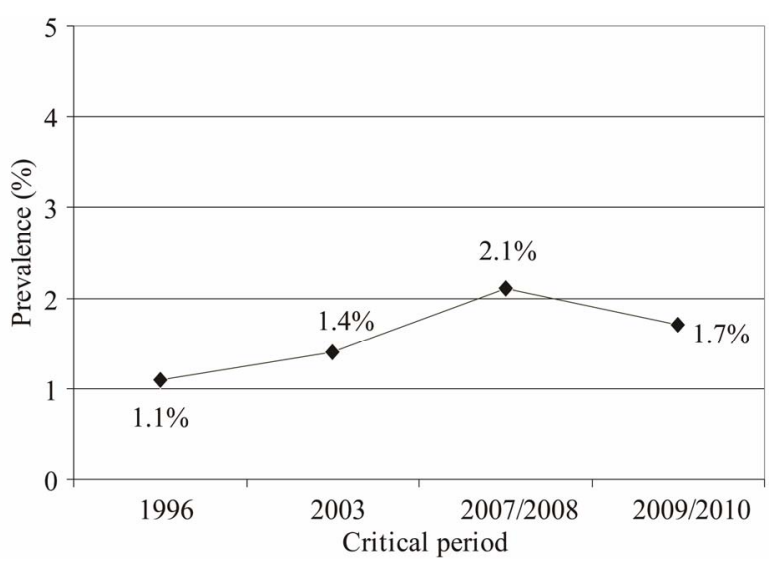

Figure 8. Prevalence of subjects with allergic asthma sensitized to common pollen allergens in the examined periods: $1.1 \%$ (1996), 1.4\% (2003), $2.1 \%$ (2007/2008), and 1.7\% (2009/ 2010).

$\mathrm{AR}$ and average yearly temperature together with change in total number of pollen grains in the critical periods 1996, 2003, 2007, and 2009 is illustrated in Figure 9. 


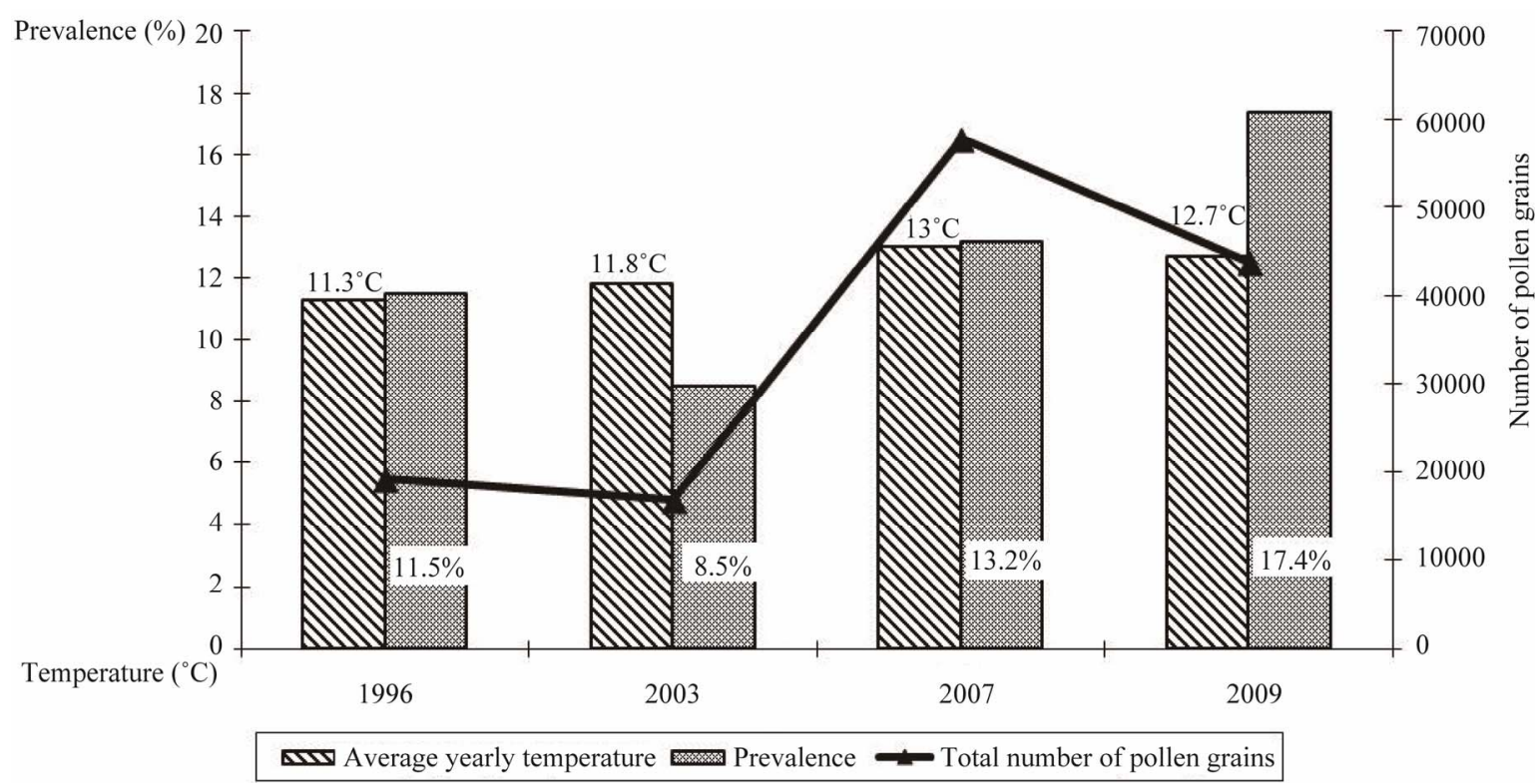

Figure 9. Prevalence of allergic rhinitis, average yearly temperature, and total number of pollen grains in the critical periods 1996, 2003, 2007, and 2009.

\section{Discussion}

Although the predictions of climate changes are uncertain and controversial, there are many attempts to derive future climate scenarios. According to the report of the Intergovermental Panel on Climate Change (IPCC) by the year 2100 many areas in the Northern Hemisphere will become warmer and wetter, i.e. the average global temperature may rise by $2.0^{\circ} \mathrm{C}$ and rising temperatures are expected to result in fewer cold days, heat waves, and increased atmospheric moisture.

In addition, climate change has the potential to have many significant impacts on aeroallergens, such as pollen and mold spores, and therefore related respiratory allergic diseases [25]. Current research has focused on examining how specific elements of climate change, such as increased carbon dioxide levels, increased maximum temperature, increased or decreased precipitations, etc, could modify the production, distribution, and allergic potential of aeroallergens $[12,26]$. On the other side, there are a number of other factors than climate change that may affect aeroallergen levels and the prevalence of associated respiratory allergies, such as air pollution, changes in land use, adaptive responses, etc., the role of which is difficult to assess.

In the present paper we assess the impact of the climate change and particularly maximum temperature on airborne pollens concentration, distribution and allergenic potential in the atmosphere of the city of Skopje in defined critical periods (1996, 2003, 2007/2008, and 2009/2010) and subsequent impact on the prevalence of sensitization to common inhalant allergens, common pollen allergens and respiratory allergies among adults in the city of Skopje in the same critical periods.

The city of Skopje is an urban center with a wide gravitational radius and the most important center in Macedonia, having concentrated one quarter of its total population. It takes the middle part of the Skopje ravine and belongs to warm continental zone. The average year temperature is $12^{\circ} \mathrm{C}$ and the average rain quantity is about $5017 \mathrm{~mm}$ per year. It is clear that the influence of the Continental-Mediterranean climate (as well as its modifications with the effects of mountain climate) is one of the most dominant factors on the vegetation of the given territory.

Aeropalinological measurements showed significant increase in the concentration of Cupressaceae pollen, as well as increase in the duration of the pollination for several pollen types in the period 1996-2009. According to the registered changes in the average maximal temperatures in the period 1994-2009, comparison of the results from the empirical downscaling and the local projections by the direct Global Circulatory Model output $[15,16]$, in R. Macedonia a more intensive increase in air temperature is expected in summer, winter and spring, associated with a strong decrease in precipitation so further changes in the pollen concentration and the duration of pollination are also expected.

We found similar prevalence of atopy in the studies performed in all critical periods $(35 \%-38 \%)$. Development of allergic disease occurs through a two-phases process. In the first phase a predisposed immunological naïve individual is sensitized to an allergen, resulting in production of $\operatorname{IgE}$ antibodies, whereas in the second 
phase, repeated exposure to the allergen elicits a disease due to the presence of $\operatorname{IgE}$ and the associated cellular response [27,28]. Atopy is defined as an inherited predisposition tendency to produce IgE antibodies in response to low doses of allergens, usually proteins, and to develop typical symptoms such as asthma, rhinoconjunctivitis, or eczema/dermatitis $[29,30]$. The degree to which an aeroallergen may cause an allergic sensitization and subsequent allergic disease in sensitized individual depends on multiple factors, i.e. endogenous factors (race, sex, age, familial history for allergic disease, etc.) and environmental factors, such as the type of aeroallergen, the amount of aeroallergen to which an individual is exposed (a dose-response relationship), air pollution, climate factors, etc $[28,31]$. The overall prevalence of atopy in the European countries varies between $30 \%$ to $50 \%$ with significant variations between regions in the same country [8].

$\mathrm{AR}$, asthma, and atopic dermatitis (the so-called atopic cluster) are the allergic diseases associated with aeroallergens [24]. Although all aeroallergens are linked to each of these allergic diseases, the strongest association is found to be between pollens and AR, as well as between house dust mite or mold and asthma $[13,24]$.

We found slight increase in the sensitization to common pollen allergens in the study performed in 2009/ 2010 as compared with results obtained in the study performed in 1996. The prevalence of sensitization to grass and weed pollens was higher than sensitization to tree pollens in the studies performed in all critical periods as a result of higher allergic potential of these pollens. Similar findings are reported in our other studies on the pattern of allergic sensitization in general population, as well as in many other studies [10,32-34].

The most common allergic disease associated with exposure to pollens is AR (hay fever), also referred to as rhinoconjunctivitis or to pollinosis. Sensitization to pollens is considered to be a primary risk factor for AR development [28]. Nevertheless, AR can develop also in the individuals sensitized to indoor allergens, such as dust mites, cockroaches, and indoor molds [28,35]. We found higher prevalence of AR in the study performed in 2009/2010 than in the previous studies. At the same time, the prevalence of the rhinitics sensitized to common pollen allergens in the studies performed in 2007/2008 and in 2009/2010 was slightly higher than their prevalence registered in the study performed in 1996.

We found non-significantly higher prevalence of asthma in the studies performed in 2009/2010 and in 2007/2008 than in the study performed in 2003, whereas the difference of the asthma prevalence in these studies was significantly higher than in the study performed in 1996. The findings about prevalence of allergic asthma were similar. The prevalence of subjects with allergic asthma sensitized to common pollen allergens in the studies per- formed in 2003, 2007/2008, and in 2009/2010 was slightly higher than their prevalence in the study performed in 1996. The etiology of asthma is complex and has a genes/environment interaction that is still poorly understood [12]. Unlike AR, which is primarily associated with exposure to pollens, it seems that allergic asthma is more strongly associated with exposure to indoor allergens and molds [28,36-39]. At the same time, some authors suggest a supporting role of exposure to pollens in the asthma development [40]. On the other side, the link between climate change and indoor allergens (e.g. mite sensitization) is unclear. Furthermore, data from Australia showed doubling of the prevalence of diagnosed asthma in the period 1971-1981 which has not been accompanied by increase in the prevalence of allergic sensitization to grass pollen and Dermatophagoides pteronyssinus [41].

The present study has some limitations. First, relatively small number of the subjects in the studies performed in the critical periods could have certain implications on the data obtained and its interpretation. Second, despite registered change in pollen micro flora, a period of 15 years could be too short for significant change in sensitization to pollen allergens and in prevalence of respiratory allergies. The strength of the study is the extensive evaluation of examined subjects by the same protocol in the defined critical periods.

In conclusion, in the serial cross-sectional studies on prevalence of atopy, sensitization to common pollen allergens, and respiratory allergies in adults in the city of Skopje in relation to the climatic change and changes in pollen micro flora performed in the defined critical periods (1996, 2003, 2007/2008, and 2009/2010) we found slight increase in the prevalence of sensitization to common pollen allergens, as well as in the prevalence of subjects with AR and allergic asthma sensitized to common pollen allergens that may be related to differences in the pollen distributions detected by aeropalinological measurements. Further monitoring and investigation are necessary to explain relation of change in pollen micro flora associated with global climatic change to prevalence of respiratory allergies in order to implement adequate preventive and adaptive strategies regarding this global public health problem.

\section{Acknowledgements}

We wish to thank WHO Country Office Skopje-Dr. Marija Kisman-Hristovska, Head of Office, and Margarita Spasenovska, National Professional Officer, for their support and helpful advices on this manuscript.

\section{REFERENCES}

[1] C. W. Brown and L. Hawkins, "Allergy Prevalence and 
Causal Factors in the Domestic Environment: Results of a Random Population Survey in the United Kingdom," Annals of Allergy, Asthma \& Immunology, Vol. 83, No. 3, 1999, pp. 240-244. doi:10.1016/S1081-1206(10)62647-6

[2] M. Kilpeläinen, E. O. Terho, H. Helenius and M. Koskenvuo, "Home Dampness, Current Allergic Diseases, and Respiratory Infections among Young Adults," Thorax, Vol. 56, No. 6, 2001, pp. 462-467.

doi:10.1136/thorax.56.6.462

[3] N. Ezova, V. Cvetanov, S. Milkovska, et al., "Characteristics of Allergic Rhinitis in R. Macedonia," Makedonski Medicinski Pregled, Vol. 56, No. 3, 2003, pp. 142-143.

[4] A. Seaton, D. J. Godden and K. Brown, "Increase in Asthma: Is a More Toxic Environment, or a More Susceptible Population," Thorax, Vol. 49, No. 2, 1994, pp. 171-174. doi:10.1136/thx.49.2.171

[5] C. Janson, P. Anto, P. Burney, et al., "The European Community Respiratory Health Survey: What Are the Main Results so Far?" European Respiratory Journal, Vol. 18, No. 3, 2001, pp. 598-611.

[6] G. Viegi, I. Annesi and G. Matteelli, "Epidemiology of asthma," European Respiratory Monograph, Vol. 8, No. 23, 2003, pp. 1-25.

[7] J. Karadzinska-Bislimovska, V. Cvetanov, J. Petrovska, et al., "Respiratory Symptoms and Positive Skin Prick Tests in a Prospective Asthma Study in Republic of Macedonia (Initial Results)," European Respiratory Journal, Vol. 14, No. 30, 1999, p. 78.

[8] J. Minov, V. Cvetanov, J. Karadzinska-Bilsimovska, et al., "Epidemiological Characteristics of Bronchial Asthma in R. Macedonia," Makedonski Medicinski Pregled, Vol. 56, No. 3, 2003, p. 156

[9] E. von Mutius and M. R. Sears, "Risk Factors for Development of Asthma," European Respiratory Monograph, Vol. 8, No. 23, 2003, pp. 57-73.

[10] E. von Mutius and M. R. Seras, "Risk Factors for Development of Asthma," European Respiratory Monograph, Vol. 8, No. 23, 2003, pp. 57-72.

[11] P. J. Beggs, "Impacts of Climate Change on Aeroallergens: Past and Future," Clinical and Experimental Allergy, Vol. 34, No. 10, 2004, pp. 50-57. doi:10.1111/j.1365-2222.2004.02061.x

[12] P. J. Beggs and H. J. Bambrick, "Is the Global Rise of Asthma an Early Impact of Anthropogenic Climate Change?" Environmental Health Perspectives, Vol. 113, No. 8, 2005, pp. 915-919. doi:10.1289/ehp.7724

[13] C. E. Reid and J. L. Gamble, "Aeroallergens, Allergic Disease, and Climate Change: Impacts and Adaptation," Ecohealth, Vol. 6, No. 3, 2009, pp. 458-470. doi:10.1007/s10393-009-0261-x

[14] J. J. McCarthy, O. F. Canziani, N. A. Leary, D. J. Dokken and K. S. White, "Intergovernmental Panel on Climate Change. Climate Change 2001: Impacts, Adaptation, and Vulnerability," Cambridge University Press, Cambridge, 2001.

[15] K. Bergant, "Climate Change Scenarios for Macedonia-Review of Methodology and Results," University of Nova
Gorica, Nova Gorica, 2006, pp. 3-4.

[16] V. Kendrovski, S. Milkovska, J. K. Bislimovska, J. Minov, M. Spasenovska and M. K. Hristovska, "The Impacts of Maximum Temperature and Climate Change to Current and Future Pollen Distribution in Skopje, Republic of Macedonia," TAF Preventive Medicine Bulletin, Vol. 11, No. 1, 2012, pp. 35-40. doi: $10.5455 / \mathrm{pmb} .20110504050151$

[17] A. Minette, "Questionnaire of the European Community for Coal and Steel (ECSC) on Respiratory Symptoms. 1987-Updating of the 1962 and 1967 Questionnaires for Studying Chronic Bronchitis and Emphysema," European Respiratory Journal, Vol. 2, No. 2, 1989, pp. 165-177.

[18] European Community Respiratory Health Survey, "Variations in the Prevalence of Respiratory Symptoms, SelfReported Asthma Attacks, and Use of Asthma Medication in the European Respiratory Health Survey (ECRHS)," European Respiratory Journal, Vol. 9, 1996, pp. 687-695. doi:10.1183/09031936.96.09040687

[19] The European Academy of Allergology and Clinical Immunology, "Position Paper: Allergen Standardization and Skin Tests," Allergy, Vol. 48, No. 14, 1993, pp. 48-82.

[20] Quajner Standardization of Lung Function Tests-1993 Update, "Report Working Party for the European Community for Steel and Coal. Official Statement of the European Respiratory Society," European Respiratory Journal, Vol. 16, No. 1, 1993, pp. 1-100.

[21] P. J. Sterk, L. M. Fabbri, D. W. Quanjer, et al., "Airway Responsiveness-Standardized Challenge Testing with Pharmacological, Physical and Senzitizing Stimuli in Adults," European Respiratory Journal, Vol. 6, No. 16, 1993, pp. 5383.

[22] American Thoracic Society, "Guidelines for Methacholine and Exercise Challenge Testing-1999," American Journal of Respiratory and Critical Care Medicine, Vol. 161, No. 1, 2000, pp. 309-329.

[23] S. Blonshine, "Assessing the Bronchodilator Response," 2010. http://www. rtmagazine.com

[24] A. J. Frew, "Allergic Basis of Asthma," European Respiratory Monograph, Vol. 23, No. 8, 2003, pp. 74-83.

[25] P. Beggs, "Adaptation to Impacts of Climate Change on Aeroallergens and Allergic Respiratory Diseases," International Journal of Environmental Research and Public Health, Vol. 7, No. 8, 2010, pp. 3006-3021. doi:10.3390/ijerph7083006

[26] G. D'Amato and L. Cecchi, "Effects of Climate Change on Environmental Factors in Respiratory Allergic Diseases," Clinical and Experimental Allergy, Vol. 38, No. 8, 2008, pp. 1264-1274. doi:10.1111/j.1365-2222.2008.03033.x

[27] D. H. Katz, "Regulation of the IgE System: Experimental and Clinic Aspects," Allergy, Vol. 39, No. 2, 1984, pp. 81-106. doi:10.1111/j.1398-9995.1984.tb01940.x

[28] G. D. Nielsen, J. S. Hansen, R. M. Lund, et al., "IgE-Mediated Asthma and Rhinitis: A Role of Allergen Exposure?" Pharmacology \& Toxicology, Vol. 90, No. 5, 2002, pp. 231-242. doi:10.1034/j.1600-0773.2002.900502.x 
[29] S. G. Johanson, J. O. Hourihane, J. Bousquet, et al., "A Revised Nomenclature for Allergy," Allergy, Vol. 56, No. 9, 2001, pp. 813-822. doi:10.1034/j.1398-9995.2001.t01-1-00001.x

[30] J. S. Fowler and B. J. Lipworth, "Relationship of Skin Prick Reactivity to Aeroallergens and Hyperresponsiveness to Challenges with Metacholine and Adenosine Monophosphate," Allergy, Vol. 58, No. 1, 2003, pp. 4651. doi:10.1034/j.1398-9995.2003.23779.x

[31] M. L. Burr, "Grass Pollen: Trends and Predictions," Clinical and Experimental Allergy, Vol. 29, No. 6, 1999, pp. 735-738. doi:10.1046/j.1365-2222.1999.00621.x

[32] V. Cvetanov, S. Milkovska, S. Risteska-Kuc, et al., "Epidemiological Characteristics of Allergic Diseases in R. Macedonia," Makedonski Medicinski Pregled, Vol. 56, No. 3, 2003 pp. 140-141.

[33] J. Sunyer, J. M. Anto, M. Kogevinas, et al., "Risk Factors for Asthma in Young Adults. Spanish Group of the European Community Respiratory Health Survey," European Respiratory Journal, Vol. 10, No. 11, 1997, pp. 24902494. doi:10.1183/09031936.97.10112490

[34] J. Sunyer, J. Soriano, J. M. Anto, et al., "Sensitization to Individual Allergens as Risk Factors for Lower FEV 1 in Young Adults. European Community Respiratory Health Survey," International Journal of Epidemiology, Vol. 29, No. 1, 2000, pp. 125-130. doi:10.1093/ije/29.1.125

[35] W. Phipatanakul, "Allergic Rhinoconjunctivitis: Epide- miology," Immunology and Allergy Clinics of North America, Vol. 25, No. 2, 2005, pp. 263-281. doi:10.1016/i.iac.2005.03.001

[36] R. G. Hamilton and P. A. Eggleston, "Environmental Allergen Analyses," Methods, Vol. 13, No. 1, 1997, pp. 5360. doi:10.1006/meth.1997.0495

[37] S. Chinn, D. Jarvis, C. Luczynska and P. Burney, "Individual Allergens as Risk Factors for Bronchial Responsiveness in Young Adults," Thorax, Vol. 53, No. 8, 1998, pp. 662-667. doi:10.1136/thx.53.8.662

[38] C. Neukrich, C. Henry, B. Leynaert, et al., "Is Sensitization to Alternaria Alternata a Risk Factor for Severe Asthma? A Population-Based Study," Journal of Allergy and Clinical Immunology, Vol. 103, No. 4, 1999, pp. 709-711.

[39] R. K. Bush and J. J. Prochnau, "Alternaria-iNDUCED ASTHMA," Journal of Allergy and Clinical Immunology, Vol. 113, No. 2, 2004, pp. 227-234. doi:10.1016/j.jaci.2003.11.023

[40] H. A. Burge, "An Update on Pollen and Fungal Spore Aerobiology," Journal of Allergy and Clinical Immunology, Vol. 110, No. 4, 2002, pp. 544-552. doi:10.1067/mai.2002.128674

[41] J. K. Peat, M. Haby, J. Spijker, et al., "Prevalence of Asthma in Adults in Busselton, Western Australia," BMJ, Vol. 305, 1992, pp. 1326-1329. doi:10.1136/bmj.305.6865.1326 